\title{
Aproveitamento de vísceras não comestíveis de aves para elaboração de farinha de carne
}

\author{
The use of non-edible poultry viscera to produce meat flour
}

\author{
Denise Pinheiro Soncini COSTA ${ }^{1 \star}$, Pedro Fernando ROMANELLI ${ }^{2}$, Elizeu TRABUCO ${ }^{3}$
}

\begin{abstract}
Resumo
No presente trabalho, estudou-se o processamento das vísceras de frango (Gallus domesticus) e das ratitas avestruz (Struthio camellus) e ema (Rhea americana), processadas da mesma forma, com o objetivo de elaborar farinhas. A qualidade e controle de produção dessas farinhas foram avaliados por meio de parâmetros tecnológicos exigidos pela legislação vigente. Basicamente, a matéria-prima foi cozida e esterilizada, filtrada em peneira (para a separação do óleo), moída, seca em estufa e analisada. Foram obtidos dados de rendimentos de produção, de composição de nutrientes, de digestibilidade em pepsina, do valor calórico, determinados os teores de cálcio e fósforo, e realizados estudos da estabilidade da farinha durante o armazenamento (Salmonella, pH, índice de acidez e TBA). Os resultados mostraram que a produção de farinha pelo processamento das vísceras de avestruz e ema é viável, seus parâmetros de qualidade atendem, em grande parte, às exigências, mas, para um emprego imediato (uso regular) na elaboração de rações, necessita de alguns ajustes (correções) de parâmetros físico-químicos (nutrientes).

Palavras-chave: farinha de vísceras; controle de produção; parâmetros de qualidade.
\end{abstract}

\begin{abstract}
This work studied the processing of the viscera of chicken (Gallus domesticus) and of the ratites ostrich (Struthio camellus) and great rhea (Rhea americana), processed in the same manner, with the objective of producing flours. The quality and control of the production of these flours were evaluated through technological parameters required by the current legislation. Basically, raw material was cooked and sterilized, sieve filtered (for oil separation), ground, dried in an oven and analyzed. Production yield, nutrient composition, pepsin digestibility and caloric value data were obtained. Calcium and phosphorus levels and flour stability during storage (Salmonella, $\mathrm{pH}$, acid value and TBA) were also determined. The results indicated that the production of flour by processing the viscera of ostrich and great rhea is viable. Quality parameters greatly fulfill requirements; however, for immediate (regular) use to prepare feed, some adjustments (corrections) must be made on physical-chemical parameters (nutrients).
\end{abstract}

Keywords: viscera flour; production control; quality parameters.

\section{Introdução}

Atualmente, em alguns países, a carne de animais silvestres é considerada um alimento exótico e desejável, por conter baixo teor calórico.

Os animais silvestres, se adequadamente manejados, podem transformar-se em fontes renováveis de produtos de grande rentabilidade, contribuir para melhorar a oferta de alimentos e competir, em custo de produção, com os animais domésticos (GIANNONI, 1998).

Vários desses animais produzem carnes com baixos teores de lipídios totais, mas com desejáveis concentrações de ácidos graxos poliinsaturados, quando comparados a alguns animais domésticos (NAUGHTON; O’DEA; SINCLAIR, 1986; SINCLAIR; O'DEA, 1990; apud BRESSAN et al., 2004; SCRIBONI, 2006).

No contexto de consumo de animais silvestres, destaca-se a carne de ratitas (avestruz, ema e emu). A criação de ratitas está surgindo como uma alternativa para a agropecuária, pois tais aves, por utilizarem alimentos de baixa qualidade, existentes em solos fracos, apresentam potencial para transformá-los em proteína animal de alto valor biológico (GIANNONI, 1998, 2001).

Nas duas últimas décadas, embora ainda modesta, a criação de emas vem conquistando espaço no mercado brasileiro, especialmente entre os pequenos e médios produtores rurais que buscam lucratividade com um investimento inicial relativamente baixo (GIANNONI, 2001).

No Brasil, a utilização de abatedouros de bovinos adaptados está sendo a opção mais barata para a otimização do abate de avestruz em condições higiênico-sanitárias satisfatórias.

Com o crescente aumento da população mundial, tornase necessária a busca por alimentos alternativos, como forma de suprir a demanda. Porém, para atingir seus objetivos, essas fontes alternativas devem não só conter alimentos nutritivos produzidos em alta escala e de baixo custo, mas também apresentar boas características sensoriais.

${ }^{1}$ Instituto de Biociências, Letras e Ciências Exatas, Universidade Estadual Paulista - UNESP, CEP 15054-000, São José do Rio Preto - SP, Brasil, E-mail: denisepinheiro@itecnet.com.br

2 Departamento de Engenharia e Tecnologia de Alimentos, Universidade Estadual Paulista - UNESP, CEP 15054-000, São José do Rio Preto - SP, Brasil

3 Departamento de Química e Ciências Ambientais, Universidade Estadual Paulista - UNESP, CEP 15054-000, São José do Rio Preto - SP, Brasil

${ }^{*}$ A quem a correspondência deve ser enviada 
Um aproveitamento racional de resíduos de animais abatidos em escala comercial (abatedouros) poderá ser feito em forma de consumo direto pelo homem, ou indireto, por meio da alimentação de animais de consumo (PARDI et al., 1993; PRICE; SCHWEIGERT, 1994; MEDEIROS et al., 2000).

O aproveitamento de resíduos pelas indústrias de transformação de produtos de origem animal pode ser um fator importante do ponto de vista econômico, tecnológico, nutricional e de saúde pública (ambiental), uma vez que os despojos podem ser fontes protéicas de origem animal e diminuir custos com seu tratamento (PARDI et al., 1993; PRICE; SCHWEIGERT, 1994).

A farinha de carne, resultante do processamento de resíduos não utilizados para consumo (despojos de carne, vísceras, órgãos, ossos, etc.), é um suprimento alimentar rico em nutrientes, constituído de proteínas de alto valor biológico, sais minerais e vitaminas do complexo B. A farinha é considerada um ingrediente nutricional primordial na elaboração de ração para animais domésticos, movimentando atualmente um crescente mercado (OCKERMAN; HANSEN, 1994; PRICE; SCHWEIGERT, 1994; ANDRIGUETTO et al., 1999).

No Brasil, a falta de uniformidade da matéria-prima de origem animal obrigou os fabricantes de ração a elaborarem uma padronização nacional. Foi a partir daí que o Sindicato Nacional da Indústria de Alimentação Animal (SINDIRAÇÕES) e a Associação Nacional de Fabricantes de Alimentos para Animais (ANFAL), com o Ministério da Agricultura, publicaram em 2005 a segunda edição do Manual de Padronização de Matéria-Prima para Alimentação Animal. Esse manual baseia-se na Lei 6.198, de 26/12/74, e no Decreto 76.986, de 6/1/76 do Ministério da Agricultura e Abastecimento, e regulamenta a inspeção e a fiscalização dos produtos destinados à alimentação animal (BRASIL, 2005).

Segundo o SINDIRAÇÕES, o Brasil é o terceiro maior produtor de ração animal, ficando atrás dos EUA e da China. No Brasil, em 2005, foram produzidos 48 milhões de toneladas, $10,6 \%$ a mais que em 2004. Em 2006, a produção de ração cresceu $4,5 \%$, quando o previsto era $10 \%$; nesse mesmo ano a avicultura consumiu 27,2 milhões de toneladas de rações, tornando-se a maior consumidora de rações, seguida pela suinocultura (13,3 milhões de toneladas) e pela bovinocultura (5,6 milhões de toneladas). Em 2007, as indústrias venderam $8,6 \%$ a mais que em 2006, o que representou 52,4 milhões de toneladas do produto, projeção que se baseou nas boas perspectivas das exportações do complexo de carne.

O interesse pelos estudos de uma exploração tecnológica mais ampla dos subprodutos de ratitas (avestruz e ema) surgiu em função da possibilidade dessa criação vir a ser uma atividade futura e promissora na avicultura brasileira. Espera-se, portanto, que os resultados desse manejo tecnológico façam estimular ainda mais o interesse pela criação e pelo desenvolvimento dessas espécies.

\section{Material e métodos}

Vísceras congeladas das três espécies: frango (Gallus domesticus), avestruz (Struthio camellus) e ema (Rhea americana) foram obtidas de abatedouros.
Foram usados 14 lotes de vísceras das três espécies assim distribuídas: cinco de frango, cinco de avestruz e quatro de ema. $\mathrm{O}$ peso de cada lote variou de $1,2 \mathrm{a} 2,5 \mathrm{~kg}$ de vísceras. Todos os lotes foram processados nas mesmas condições experimentais (tempo e temperatura).

No cálculo de rendimentos (óleo, resíduos totais e farinha), após o processamento, utilizou-se o peso das vísceras descongeladas, como referência.

As vísceras de cada espécie foram descongeladas, tomadas ao acaso, homogeneizadas, pesadas, cozidas e/ou esterilizadas em autoclave $\left(121^{\circ} \mathrm{C} / 20\right.$ minutos), formando lotes. O conteúdo autoclavado, constituído por vísceras cozidas sem fragmentar (resíduo sólido grosso) e por vísceras fragmentadas (resíduo sólido fino) contendo óleo incorporado, foi resfriado à temperatura ambiente e passado em peneira $(2 \mathrm{~mm})$, para separar o resíduo sólido grosso das vísceras fragmentadas. Estas foram centrifugadas (3000 rpm/60 minutos) para a separação do óleo e, posteriormente, o resíduo sólido fino obtido foi incorporado ao resíduo grosso.

Após a incorporação, o resíduo total (grosso e fino) foi triturado (moedor de carne ${ }^{1}$ ), homogeneizado e seco em estufa com circulação de ar $\left(80^{\circ} \mathrm{C} / 6\right.$ horas). O material seco resultante foi moído em liquidificador (caseiro), submetido à análise granulométrica (peneira $2 \mathrm{~mm}$ ), pesado, armazenado ${ }^{2}$ e devidamente identificado para avaliações posteriores de qualidade (análises físico-química, microbiológica e de estabilidade).

Os métodos utilizados para as avaliações de controle de qualidade da farinha elaborada (realizadas em duplicata) apresentam-se de acordo com as metodologias recomendadas pela Legislação (BRASIL, 2005).

O teor de nitrogênio total foi analisado pelo método Micro-Kjeldahl, com o emprego do fator 6,25 para o cálculo do teor protéico.

O percentual de umidade foi determinado pelo método de secagem em estufa $\left(100-105^{\circ} \mathrm{C}\right)$, até peso constante.

A análise de digestibilidade em pepsina foi determinada de acordo com metodologia recomendada para subprodutos de origem animal (BRASIL, 2005).

Para a determinação do teor de lipídios, empregou-se o método de Bligh e Dyer (1959).

A quantidade de cinzas foi determinada por incineração em mufla a $550^{\circ} \mathrm{C}$ (CUNNIFF, 1997; BRASIL, 2005).

A quantificação dos elementos cálcio e fósforo foi feita a partir do tratamento das cinzas com uma solução preparada pela mistura de água e ácido clorídrico concentrado (37\%), na proporção de 1:1, que, após aquecimento, filtração e diluição, foi armazenada. A quantidade de cálcio foi determinada por oxidimetria, nesse processo as amostras sob aquecimento foram tituladas com solução padronizada de permanganato de potássio (BRASIL, 2005). Avaliou-se o fósforo pela reação das amostras com os reagentes metavanadato de amônio e molibdato de

\footnotetext{
${ }^{1}$ Marca Bermar - modelo semi-industrial (açougue) contendo disco $5 \mathrm{~mm}$.

${ }^{2}$ Frasco escuro (negro) com boca dotada de fechos herméticos, tipo vedapack (boca ${ }^{\circ} 3$ ).
} 
amônio (presentes nas mesmas proporções); posteriormente, foi feita a determinação espectrofotométrica dos resultados, a $420 \mathrm{~nm}$. Determinou-se, assim, a porcentagem de fósforo com o emprego de uma curva-padrão (CUNNIFF, 1997; BRASIL, 2005).

$\mathrm{Na}$ avaliação da porcentagem de fibra, as amostras foram digeridas por refluxo inicialmente com solução aquosa de ácido sulfúrico $(1,25 \%)$ e depois com solução aquosa de hidróxido de sódio (1,25\%); na seqüência, essas amostras foram quantificadas por gravimetria (CUNNIFF, 1997; BRASIL, 2005).

Os carboidratos foram determinados por diferença, conforme a literatura (JAMES, 1996).

Os valores energéticos das farinhas foram obtidos por cálculos baseados nas médias dos resultados de proteínas, lipídios e carboidratos, aplicando-se os fatores de Atwater para carne (MERRIL; WATT, 1975; OLIVEIRA; SANTOS; WILSON, 1982).

A avaliação granulométrica foi realizada em aparelho vibrador equipado com o conjunto de peneiras ${ }^{3}$ sobrepostas em ordem decrescente de abertura de malhas (BRASIL, 2005).

A estabilidade da farinha ao longo do tempo de armazenamento (vida de prateleira) foi monitorada nos períodos de 0,7 , 15 e 30 dias. Foram considerados os seguintes parâmetros:

- oxidação lipídica (teste TBA - ácido 2-tiobarbitúrico). A amostra (farinha $\cong 10 \mathrm{~g}$ ) suspensa em $50 \mathrm{~mL}$ de TCA (ácido tricloroacético 7,5\%) foi homogeneizada (1 minuto) e filtrada (papel de filtro). Em tubos de ensaio, colocaram-se $4 \mathrm{~mL}$ desse filtrado, $1 \mathrm{~mL}$ de TCA e $5 \mathrm{~mL}$ de TBA (ácido tiobarbitúrico). Os tubos foram colocados em água fervente (40 minutos) e esfriados à temperatura ambiente. Em seguida, procedeu-se à análise espectrofotométrica a 538 nm (ROSMINI et al., 1996);

- o índice de acidez foi determinado por titulação da amostra com uma base ( $\mathrm{NaOH}$ 0,1M) e com fenolftaleína como indicador (BRASIL, 2005);

- $\mathrm{pH}$, com uso de pHmetro (DUTSON, 1983); e

- a qualidade microbiológica da farinha armazenada foi determinada pela presença/ausência de Salmonella spp., após 30 dias de armazenamento, utilizando a metodologia recomendada na literatura para produtos e subprodutos de origem animal, rações e concentrados (BRASIL, 2005).

As análises estatísticas foram realizadas conforme a literatura (PAGANO; GAUVREAU, 2004).

Aos resultados do rendimento de óleo, porcentagem de umidade, carboidrato, digestibilidade em pepsina e $\mathrm{pH}$, foram aplicados Testes de Análise de Variância e Comparações Múltiplas de Tukey, a partir de um delineamento inteiramente casualizado com números diferentes de repetições. Para a variável retenção em peneira, foi aplicado o teste utilizando a transformação arco seno da raiz da proporção (p). Nas variáveis rendimento dos resíduos totais, perda, farinha, proteína, lipídio, cinza, fibra, cálcio, fósforo, TBA e acidez, por não existir

${ }^{3} 7 \mathrm{mesh}(2,83 \mathrm{~mm}) ; 8$ mesh (2,38 mm); 10 mesh (2,00 mm); 12 mesh (1,68 mm); e 14 mesh $(1,41 \mathrm{~mm})$. estabilidade da variabilidade (homocedasticidade), optou-se pela utilização do Teste não-paramétrico de Kruskall-Wallis, para comparar os 3 grupos (frango, avestruz e ema) e pelo teste Mann-Whitney, para comparar as medianas duas a duas.

\section{Resultados e discussão}

Para avaliar a qualidade e o padrão das farinhas das vísceras elaboradas (frango, avestruz e ema), foram utilizadas, como parâmetros de qualidade, as exigências da Lei 6.198, de 26/12/74, e do Decreto 76.986, de 6/1/76, do Ministério da Agricultura e Abastecimento, que regulamenta a inspeção e a fiscalização dos produtos destinados a alimentação animal (BRASIL, 2005). O Quadro 1 apresenta os parâmetros de qualidade da farinha de vísceras de aves, conforme exigência para comercialização.

Como resultado do processamento das vísceras das três espécies estudadas, a Tabela 1 mostra os rendimentos percentuais dos componentes intermediários normalmente presentes no processamento. À primeira vista, o maior valor do componente "resíduos totais" das ratitas poderia ser interpretado como indicador de rendimentos maiores de obtenção de farinha, porque os resíduos totais são os precursores do aparecimento de farinha. Mas a existência de soluções de compensações (contorno) estatísticas finais indica resultados de rendimento de igualdade entre as farinhas das três espécies (Tabela 2).

Em relação ao rendimento, as perdas consideradas podem ser atribuídas a perdas durante o processamento tais como: manipulação, moagem, filtração, transferência de material e

Quadro 1. Parâmetros de controle de qualidade para farinha de vísceras de aves.

\begin{tabular}{|lc|}
\hline \multicolumn{1}{|c|}{ Parâmetros } & Farinha de vísceras \\
Umidade (máximo) & $8 \%$ \\
Proteína bruta (mínimo) & $55 \%$ \\
Lipídios (mínimo) & $10 \%$ \\
Matéria mineral (máximo) & $15 \%$ \\
Cálcio (máximo) & $5 \%$ \\
Fósforo (mínimo) & $1,5 \%$ \\
Digestibilidade em pepsina & $60 \%$ \\
(1:10000 a 0,02\% em HCl 0,075 M.L-1) & \\
(mínimo) & \\
Acidez (máximo) & $3 \mathrm{mg} \mathrm{NaOH} / \mathrm{g}$ \\
Salmonella & Ausência em $25 \mathrm{~g}$ \\
Retenção em peneira 2 mm (máximo) & $5 \%$ \\
\hline
\end{tabular}

Fonte: BRASIL, 2005.

Tabela 1. Componentes intermediários do processamento das vísceras em relação ao peso das vísceras descongeladas.

\begin{tabular}{lccc}
\hline & \multicolumn{3}{c}{ Rendimento (\%) } \\
\cline { 2 - 4 } & $\begin{array}{c}\text { Vísceras de } \\
\text { frango }\end{array}$ & $\begin{array}{c}\text { Vísceras de } \\
\text { avestruz }\end{array}$ & $\begin{array}{c}\text { Vísceras de } \\
\text { ema }\end{array}$ \\
\hline Óleo $^{*}$ & $43,07^{\mathrm{a}} \pm 1,94$ & $30,78^{\mathrm{b}} \pm 1,83$ & $27,09^{\mathrm{b}} \pm 4,36$ \\
Resíduos totais $\pm 1,84^{\mathrm{a}} \pm 2,41$ & $56,41^{\mathrm{b}} \pm 1,40$ & $56,01^{\mathrm{b}} \pm 5,79$ \\
Perda & $9,09^{\mathrm{a}} \pm 0,69$ & $12,81^{\mathrm{b}} \pm 1,78$ & $16,90^{\mathrm{b}} \pm 3,86$ \\
\hline
\end{tabular}

Os resultados são médias com as respectivas estimativas de desvio padrão; ${ }^{*}$ letras diferentes na mesma linha - diferença significativa $(\mathrm{p}<0,05)$ pelo teste de Tukey; ${ }^{*}$ letras iguais na mesma linha - diferença não significativa $(p>0,05)$; letras diferentes na mesma linha diferença significativa $(\mathrm{p}<0,05)$ pelo teste de Mann-Whitney; e letras iguais na mesma linha - diferença não significativa $(\mathrm{p}>0,05)$. 
perda de água. Em escala industrial essas perdas devem ser minimizadas para melhorar o rendimento de algum componente de maior interesse econômico.

Da Tabela 2, pode-se visualizar a implantação nos abatedouros de ratitas (ema e avestruz) do processamento das vísceras, com os mesmos objetivos e lucratividade aos já existentes para o frango. Dessa forma, o aproveitamento das vísceras é uma realidade tecnológica viável, um subproduto de renda adicional para abatedouros, tal como acontece hoje com o frango, uma espécie cujos despojos são de fácil comércio e de uso já consagrado na alimentação animal.

Price e Schweigert (1994) citam rendimentos médios estimados de farinhas de frango (mistura de subprodutos, carne e ossos) em $4,6 \%$ por $100 \mathrm{~kg}$ de peso vivo corporal. Schneider (1973) mostra rendimento de farinha de subprodutos de frango na faixa de 10 a $12 \%$ do peso vivo do animal. Jorge Neto (1994) comenta rendimento de produção de farinha de vísceras de frango variando entre 2,8 e 4,4\% do peso vivo da ave abatida. Esses dados não permitem uma relação direta com os resultados deste trabalho, que mostra valores de rendimentos calculados com base no peso das vísceras e não no peso corporal das aves.

A Granolumetria (Tabela 3) é um parâmetro de controle de fácil solução, pois quando se apresenta fora da especificação, pode-se realizar uma nova moagem e/ou uma adequação dos equipamentos para que se cumpra a granulometria exigida, porém as adaptações e/ou correções geram um custo adicional no processo, nem sempre desejado.

A Tabela 4 mostra os resultados obtidos, no presente trabalho, para a composição centesimal dos nutrientes das farinhas de vísceras de frango, avestruz e ema.

O valor de umidade da farinha obtido pelo controle de secagem durante o processamento influencia na estabilidade do produto (vida de prateleira) e conseqüentemente na sua aceitação para comercialização. Dessa forma, é possível processar vísceras de ratitas em escala industrial e com umidade equivalente ao da farinha de frango, uma farinha bem aceita.

Os resultados da literatura, em relação à umidade, não fazem referência ao controle de umidade durante o processamen-

Tabela 2. Rendimento final das farinhas de vísceras de frango, avestruz e ema, em relação ao peso das vísceras descongeladas.

\begin{tabular}{ccc}
\hline \multicolumn{3}{c}{ Rendimento (\%) } \\
$\begin{array}{c}\text { Farinha de } \\
\text { vísceras de frango }\end{array}$ & $\begin{array}{c}\text { Farinha de } \\
\text { vísceras de avestruz }\end{array}$ & $\begin{array}{c}\text { Farinha de } \\
\text { vísceras de ema }\end{array}$ \\
\hline $14,35^{\mathrm{a}} \pm 0,66$ & $15,02^{\mathrm{a}} \pm 1,19$ & $15,76^{\mathrm{a}} \pm 1,98$ \\
\hline $\begin{array}{l}\text { Os resultados são médias com as respectivas estimativas de desvio padrão; e letras iguais } \\
\text { na mesma linha - diferença não significativa (p }>0,05) \text { pelo Teste de Tukey. }\end{array}$
\end{tabular}

Tabela 3. Valores de retenção em peneira $2 \mathrm{~mm}$ das farinhas de vísceras de frango, avestruz e ema.

\begin{tabular}{cccc}
\hline Farinha de vísceras & Frango & Avestruz & Ema \\
\hline Retenção em peneira $2 \mathrm{~mm}(\%)$ & $0,28^{\mathrm{a}} \pm 0,16$ & $1,12^{\mathrm{b}} \pm 0,82$ & $1,50^{\mathrm{b}} \pm 0,92$ \\
\hline $\begin{array}{l}\text { Os resultados são médias com as respectivas estimativas de desvio padrão; e letras diferentes } \\
\text { na mesma linha - diferença significativa }(\mathrm{p}<0,05) \text { pelo teste de Tukey; e letras iguais na } \\
\text { mesma linha - diferença não significativa }(\mathrm{p}>0,05) .\end{array}$
\end{tabular}

to. Na maioria dos casos, a farinha foi adquirida pronta para uso posterior na elaboração de rações, e assim foi avaliado apenas o teor de umidade da farinha já processada. Os valores de umidade de farinha de vísceras de frango apresentados na literatura variaram de 4,6\% (GONÇALVES; CARNEIRO, 2003) até 9,1\% (NYINA-WAMWIZA; WATHELET; KESTEMONT, 2007).

Com relação a outras espécies, Anderson et al. (1997) avaliaram a umidade da farinha de peixe (elaborada a partir de peixe de qualidade inferior e sobras de sardinha - Clupea harengus - peixe cultivado no Canadá) e observaram uma variação de 5,1 a 6\%. Possivelmente, essa variação de umidade esteja relacionada ao processo de cozimento $\left(88^{\circ} \mathrm{C} / 10\right.$ minutos $)$ e secagem $\left(88^{\circ} \mathrm{C} / 60\right.$ a 90 minutos), e as condições de secagem (temperatura e tempo de cozimento) diferentes ao do presente trabalho, o que justifica em parte a umidade ligeiramente maior que da farinha de frango.

Apesar da porcentagem de proteína das farinhas de avestruz e ema não atenderem às exigências, os valores de digestibilidade em pepsina revelam a possibilidade de um aproveitamento metabólico da proteína bastante favorável (Tabela 5), pois quanto maior o coeficiente de digestibilidade da proteína maior a biodisponibilidade de aminoácidos essenciais.

Os valores de concentração de proteína em farinha de vísceras de frango, encontrados na literatura variaram entre 35\% (NYINA-WAMWIZA; WATHELET; KESTEMONT, 2007) e 68,4\% (FARIA; HAYASHI; SOARES, 2002).

Por outro lado, a farinha de resíduos de peixe produzida por Anderson et al. (1997), a partir de sardinha, apresentou um teor de proteína bruta que variou de 74,6 a 77,2\%.

Tabela 4. Composição de nutrientes das farinhas de vísceras de frango, avestruz e ema.

\begin{tabular}{lrrr}
\hline & \multicolumn{3}{c}{ Nutrientes (\%) } \\
\cline { 2 - 4 } & $\begin{array}{c}\text { Farinha de } \\
\text { vísceras de } \\
\text { frango }\end{array}$ & $\begin{array}{c}\text { Farinha de } \\
\text { vísceras de } \\
\text { avestruz }\end{array}$ & $\begin{array}{c}\text { Farinha de } \\
\text { vísceras de ema }\end{array}$ \\
\hline Umidade • & $5,53^{\mathrm{a}} \pm 1,17$ & $3,52^{\mathrm{a}} \pm 1,40$ & $3,58^{\mathrm{a}} \pm 1,11$ \\
Proteína & $60,74^{\mathrm{a}} \pm 1,40$ & $47,59^{\mathrm{b}} \pm 4,80$ & $51,42^{\mathrm{b}} \pm 2,51$ \\
Lipídio & $27,07^{\mathrm{a}} \pm 1,21$ & $20,06^{\mathrm{a}} \pm 6,83$ & $32,89^{\mathrm{b}} \pm 5,30$ \\
Cinza & $4,34^{\mathrm{a}} \pm 0,16$ & $17,49^{\mathrm{b}} \pm 4,16$ & $6,26^{\mathrm{c}} \pm 2,12$ \\
Fibra & $0,78^{\mathrm{a}} \pm 0,06$ & $5,06^{\mathrm{b}} \pm 0,82$ & $3,18^{\mathrm{c}} \pm 0,73$ \\
${ }^{*}$ Carboidratos $\bullet$ & $1,54^{\mathrm{a}} \pm 0,77$ & $6,28^{\mathrm{b}} \pm 0,88$ & $2,67^{\mathrm{a}} \pm 1,16$ \\
\hline
\end{tabular}

Os resultados são médias com as respectivas estimativas de desvio padrão; • letras diferentes na mesma linha - diferença significativa $(\mathrm{p}<0,05)$ pelo teste de Tukey; • letras iguais na mesma linha - diferença não significativa ( $p>0,05)$; letras diferentes na mesma linha - diferença significativa $(\mathrm{p}<0,05)$ pelo teste de Mann-Whitney; letras iguais na mesma linha - diferença não significativa $(p>0,05)$; $e^{\star}$ determinado por diferença de acordo com James (1996).

Tabela 5. Digestibilidade em pepsina das farinhas de vísceras de frango, de avestruz e de ema.

\begin{tabular}{ccc}
\hline \multicolumn{3}{c}{ Digestibilidade em pepsina (\%) } \\
\hline $\begin{array}{c}\text { Farinha de } \\
\text { vísceras de frango }\end{array}$ & $\begin{array}{c}\text { Farinha de } \\
\text { vísceras de avestruz }\end{array}$ & $\begin{array}{c}\text { Farinha de } \\
\text { vísceras de ema }\end{array}$ \\
\hline $82,44^{\mathrm{ab}} \pm 1,58$ & $84,64^{\mathrm{a}} \pm 2,82$ & $78,64^{\mathrm{b}} \pm 2,45$ \\
\hline
\end{tabular}

Os resultados são médias com as respectivas estimativas de desvio padrão; letras diferentes na mesma linha - diferença significativa $(\mathrm{p}<0,05)$ pelo teste de Tukey; e letras iguais na mesma linha - diferença não significativa $(\mathrm{p}>0,05)$. 
Em relação ao percentual de lipídios em farinha de vísceras de frango na literatura, encontram-se valores de 4\% (GONÇALVES; CARNEIRO, 2003) a 20,2\% (BRUMANO et al., 2006).

O teor de lipídios da farinha de peixe originada da sardinha, segundo Anderson et al. (1997), variou de 11,3 a 12\%.

O teor de minerais da farinha de vísceras é um parâmetro muito importante, mas bastante polêmico pela facilidade da ocorrência de fraude, com a adição de areia, sal e excesso da farinha de osso; uma farinha barata e abundante no comércio de farinha. O procedimento da adição muitas vezes aceito e legalizado comercialmente é, portanto, muito fiscalizado (ANDRIGUETTO et al., 1999).

$\mathrm{O}$ alto teor de cinzas da farinha de vísceras de avestruz pode estar ligado a sua dieta, às características do ambiente onde viviam e à voracidade.

Sobre o percentual de cinzas em farinhas de vísceras de frango na literatura, encontram-se valores entre 6,2\% (SOUZA; CAMARÃO; REGO, 2000) e 24,6\% (NUNES et al., 2005). Provavelmente, a essa farinha com $24,6 \%$ de cinzas foram incorporadas farinhas de ossos e de tecidos tendinosos permitidas em algumas situações. E Anderson et al. (1997) também determinaram o teor de cinzas da farinha do peixe sardinha entre 12,4 e $13,6 \%$.

Apesar do Manual de Padronização de Matéria-Prima para Alimentação Animal (2005) não fazer referência à fibra na farinha de vísceras de aves, esse componente aparece em concentrações relativamente altas na farinha de vísceras das ratitas, fato justificado em parte pela alimentação nada convencional no cativeiro de contenção dessas aves, onde certamente também se alimentavam de vegetais presentes (gramíneas, folhas, mucilagem, etc.). Admite-se, então, que, em futuras criações de ratitas, com essas espécies já totalmente domesticadas e com o manejo ambiental e alimentar otimizado, a alimentação será praticamente à base de ração balanceada. Dessa forma, espera-se que o teor de fibra seja mais próximo ao encontrado hoje para a farinha de vísceras de frango de corte, com alimentação somente à base de ração balanceada. A fibra é, porém, um componente que atualmente ocupa espaço significativo na relação percentual total (100\%) dos nutrientes encontrados na farinha elaborada.

De fato, na literatura sobre farinha de vísceras de frango, as maiores concentrações de fibra nas citações não chegam a 1,5\%, o que parece reforçar essas suposições. Foram encontrados os seguintes valores: 0,6\% (BRUMANO et al., 2006), 0,7\% (NUNES et al., 2005), 1,3\% (FARIA; HAYASHI; SOARES, 2002) e 1,3\% (NASCIMENTO et al., 2002).

A Tabela 6 mostra os valores de cálcio e fósforo para as espécies de aves estudadas, os teores de fósforo estão abaixo dos padrões exigidos. Dessa forma, as farinhas das três espécies, para serem incorporadas em rações animais, deverão ser enriquecidas com fósforo.

Souza, Camarão e Rego (2000) e Brumano et al. (2006) avaliaram a porcentagem de cálcio da farinha de vísceras de frango em 0,3 e $4,7 \%$, respectivamente; valores que se encontram dentro dos padrões exigidos. Entretanto Nunes et al. (2005) identificaram valores de $9,6 \%$, resultado que certamente
Tabela 6. Valores de cálcio e fósforo das farinhas de vísceras de frango, de avestruz e de ema.

\begin{tabular}{lccc}
\hline & $\begin{array}{c}\text { Farinha de } \\
\text { vísceras de frango }\end{array}$ & $\begin{array}{c}\text { Farinha de } \\
\text { vísceras } \\
\text { de avestruz }\end{array}$ & $\begin{array}{c}\text { Farinha de } \\
\text { vísceras de ema }\end{array}$ \\
\hline Cálcio (\%) & $0,21^{\mathrm{a}} \pm 0,00$ & $1,10^{\mathrm{b}} \pm 0,04$ & $0,11^{\mathrm{c}} \pm 0,00$ \\
Fósforo (\%) & $1,10^{\mathrm{a}} \pm 0,04$ & $0,97^{\mathrm{b}} \pm 0,10$ & $0,51^{\mathrm{c}} \pm 0,03$ \\
\hline
\end{tabular}

Os resultados são médias com as respectivas estimativas de desvio padrão; letras diferentes na mesma linha - diferença significativa $(\mathrm{p}<0,05)$ pelo teste de Mann-Whitney; e letras iguais na mesma linha - diferença não significativa $(\mathrm{p}>0,05)$.

contribuiu com o alto teor de cinzas, $24,6 \%$, encontrado nas mesmas amostras.

A farinha de peixe elaborada a partir de resíduos de sardinha produzida por Anderson et al. (1997) apresenta teor de cálcio oscilando entre 3 e $4,1 \%$, valores que podem ser indicadores do alto teor de cinzas (12,4 a 13,6\%). Segundo Hildebrand (1995), os peixes têm três tipos de tecidos duros: esmalte, dentina e osso, os quais são compostos de cristais alongados de hidroxiapatita $\left[3\left(\mathrm{Ca}_{3} \mathrm{PO}_{4}\right)_{2} \cdot \mathrm{Ca}(\mathrm{OH})_{2}\right]$, o que pode justificar essa alta porcentagem de cálcio encontrado em farinhas de peixes.

Com relação ao teor de fósforo, conforme Souza, Camarão e Rego (2000) a farinha de víscera de frango contém $0,9 \%$ de fósforo (cinzas 6,2\%). Nunes et al. (2005) e Brumano et al. (2006) observaram em farinhas de vísceras de frango 4 e 2,3\% de fósforo, respectivamente, os quais se enquadram nos parâmetros de qualidade. Observa-se que estes teores de fósforo podem estar relacionados aos altos teores de cinzas 24,6 e 10,9\%, respectivamente.

Anderson et al. (1997) verificaram uma variação de 2,3 a 2,5\% de fósforo na farinha de peixe de sardinha, resultados que podem estar ligados aos altos teores de cinzas (12,4 a 13,6\%) e à presença de fósforo nos tecidos duros dos peixes, os quais são compostos de hidroxiapatita, conforme mencionado anteriormente.

Apesar da relevância do valor energético no balanceamento da ração, o Manual de Padronização de Matéria-Prima para Alimentação Animal (2005) não faz referência a limites de valor calórico para as farinhas de vísceras de aves.

Pela Tabela 7, observa-se que a farinha de vísceras de ema fornece um valor calórico maior $\left(22060,6 \mathrm{~kJ} \cdot \mathrm{kg}^{-1}\right)$, seguida pela de frango $\left(21335,3 \mathrm{~kJ} \cdot \mathrm{kg}^{-1}\right)$ e de avestruz $\left(17155,1 \mathrm{~kJ} . \mathrm{kg}^{-1}\right)$, valores que estão praticamente relacionados à concentração de lipídios e proteínas.

Meurer, Hayashi e Boscolo (2003) e Pezzato et al. (2002) determinaram o valor energético da farinha de vísceras de frango usando bomba calorimétrica segundo metodologia descrita por Silva (1990) e obtiveram valores semelhantes em 5063,9 e 5090 kcal. $\mathrm{kg}^{-1}$, respectivamente.

Como preconizado pelo Manual de Padronização de Matéria-Prima para Alimentação Animal (2005), é imprescindível a ausência de Salmonella spp. em $25 \mathrm{~g}$ do produto. As farinhas das três espécies apresentaram ausência de Salmonella spp. em $25 \mathrm{~g}$ após 30 dias de armazenamento, resultado este que demonstra uma ótima estabilidade microbiológica dessas farinhas. 
Em relação à estabilidade aparente, a acidez (Tabela 8) ao longo de 30 dias é plenamente justificável pelo tratamento térmico realizado na farinha (autoclavagem e secagem), o que praticamente inativou a enzima lípase e a manteve sem atividade ao longo do período.

Neste estudo, verificamos que a acidez, o pH e a oxidação lipidica, ao longo dos 30 dias de armazenamento, não oscilou estatisticamente para cada uma das espécies (Tabelas 8, 9 e 10). Observou-se apenas uma variação de valores entre as espécies.

Para diminuir a oxidação lipídica, o Compêndio Brasileiro de Alimentação Animal (BRASIL, 2005) sugere a adição de antioxidantes, pois a oxidação, além de provocar desenvolvimento de odor e paladar desagradável, desencadeia perdas nutricionais tais como: polimerização, saturação e perda da atividade vitamínica.

De acordo com Anderson et al. (1997) o TBA em farinha de peixe (produzido a partir de sardinha cultivada no mar) oscilou entre 2,9 mg MA(malonaldeido)/kg de amostra e 3,6 mg MA/kg de amostra.

Bragadóttir, Pálmadóttir e Kritbergsson (2004) encontraram valores de TBA na farinha de peixe capelin, durante quatro meses de armazenamento, de 1 a $4 \mathrm{mg} \mathrm{MA} / \mathrm{kg}$. Verificaram também que a farinha produzida com peixes capturados no verão e primavera não apresentaram diferenças significativas, mas a produzida no outono teve o número de TBA diminuído em 40\% (após dois meses de armazenamento, de 2,3 para $1,4 \mathrm{mg} \mathrm{MA} / \mathrm{kg}$ ). Por outro lado, a farinha produzida no inverno teve o valor de TBA praticamente duplicado em dois meses (de 2 para $4 \mathrm{mg} \mathrm{MA} / \mathrm{kg}$ ). Os autores citam que, apesar do índice de TBA ser freqüentemente usado, não tem sido considerado como índice de oxidação lipídica para produtos secos estocados. De acordo com os mesmos autores, o TBA mede produtos secundários da oxidação lipídica, principalmente malonaldeído. $\mathrm{O}$ fato de o TBA diminuir durante o tempo de estocagem da farinha implica que o malonaldeído se decompõe com o tempo ou promove reações secundárias. Porém, no presente trabalho, os valores de TBA não apresentaram variações significativas ao longo do período de armazenamento.

\section{Conclusões}

Os resultados mostraram que o processamento das vísceras de avestruz e de ema é viável em relação à elaboração de farinha de vísceras. Foi observado também que os parâmetros de qualidade físico-química, microbiológica e estabilidade durante o armazenamento atendem quase à totalidade das exigências.

Tabela 7. Determinação do valor energético* das farinhas de vísceras de frango, de avestruz e de ema.

\begin{tabular}{|c|c|c|c|c|c|c|}
\hline & \multicolumn{2}{|c|}{ Farinha de vísceras de frango } & \multicolumn{2}{|c|}{ Farinha de vísceras de avestruz } & \multicolumn{2}{|c|}{ Farinha de vísceras de ema } \\
\hline & kcal. $\mathrm{kg}^{-1}$ & $\mathrm{~kJ} \cdot \mathrm{kg}^{-1}$ & kcal.kg ${ }^{-1}$ & $\mathrm{~kJ} \cdot \mathrm{kg}^{-1}$ & kcal. $\mathrm{kg}^{-1}$ & $\mathrm{~kJ} \cdot \mathrm{kg}^{-1}$ \\
\hline Proteína & 2593,4 & 10854,2 & 2032,1 & 8504,3 & 2195,6 & 9188,7 \\
\hline Lipídio & 2441,7 & 10216,2 & 1809,4 & 7570,6 & 2966,7 & 12412,7 \\
\hline Carboidrato & 63,3 & 264,9 & 258,2 & 1080,2 & 109,7 & 459,2 \\
\hline Valor energético total & 5098,4 & 21335,3 & 4099,7 & 17155,1 & 5272,0 & 22060,6 \\
\hline
\end{tabular}

${ }^{*}$ Cálculo com base nos resultados da Tabela 4 .

Tabela 8. Índice de acidez das farinhas de vísceras de frango, de avestruz e de ema ( $\mathrm{mg} \mathrm{NaOH} / \mathrm{g})$.

\begin{tabular}{ccccc}
\hline Farinha de vísceras de & 0 dia & 7 dias & 15 dias & 30 dias \\
\hline Frango & $9,40^{\mathrm{a}} \pm 0,25$ & $9,02^{\mathrm{a}} \pm 0,68$ & $9,27^{\mathrm{a}} \pm 0,92$ & $8,57^{\mathrm{a}} \pm 0,83$ \\
Avestruz & $3,00^{\mathrm{b}} \pm 0,39$ & $2,97^{\mathrm{b}} \pm 0,28$ & $3,02^{\mathrm{b}} \pm 0,17$ & $2,92^{\mathrm{b}} \pm 0,17$ \\
Ema & $7,02^{\mathrm{c}} \pm 2,40$ & $6,87^{\mathrm{c}} \pm 2,22$ & $6,80^{\mathrm{c}} \pm 2,63$ & $6,77^{\mathrm{c}} \pm 2,39$ \\
\hline
\end{tabular}

Os resultados são médias com as respectivas estimativas de desvio padrão; letras diferentes na mesma linha - diferença significativa (p < 0,05) pelo teste de Tukey; e letras iguais na mesma linha - diferença não significativa $(\mathrm{p}>0,05)$.

Tabela 9. $\mathrm{pH}$ das farinhas de vísceras de frango, de avestruz e de ema.

\begin{tabular}{ccccc}
\hline Farinha de vísceras & 0 dia & 7 dias & 15 dias & 30 dias \\
\hline Frango & $6,32^{\mathrm{a}} \pm 0,05$ & $6,32^{\mathrm{a}} \pm 0,05$ & $6,32^{\mathrm{a}} \pm 0,05$ & $6,30^{\mathrm{a}} \pm 0,00$ \\
Avestruz & $7,00^{\mathrm{b}} \pm 0,08$ & $7,05^{\mathrm{b}} \pm 0,11$ & $7,05^{\mathrm{b}} \pm 0,11$ & $7,05^{\mathrm{b}} \pm 0,11$ \\
Ema & $6,07^{\mathrm{c}} \pm 0,05$ & $6,07^{\mathrm{c}} \pm 0,05$ & $6,10^{\mathrm{c}} \pm 0,08$ & $6,07^{\mathrm{c}} \pm 0,05$ \\
\hline
\end{tabular}

Os resultados são médias com as respectivas estimativas de desvio padrão; letras diferentes na mesma linha - diferença significativa (p < 0,05) pelo teste de Tukey; e letras iguais na mesma linha - diferença não significativa $(\mathrm{p}>0,05)$.

Tabela 10. TBA das farinhas de vísceras de frango, de avestruz e de ema (mg MA/kg amostra).

\begin{tabular}{ccccc}
\hline Farinha de vísceras & 0 dia & 7 dias & 15 dias & 30 dias \\
\hline Frango & $1,57^{\mathrm{a}} \pm 0,31$ & $1,64^{\mathrm{a}} \pm 0,36$ & $1,88^{\mathrm{a}} \pm 0,59$ & $1,97^{\mathrm{a}} \pm 0,66$ \\
Avestruz & $0,67^{\mathrm{b}} \pm 0,11$ & $0,62^{\mathrm{b}} \pm 0,08$ & $0,62^{\mathrm{b}} \pm 0,04$ & $0,64^{\mathrm{b}} \pm 0,05$ \\
Ema & $2,15^{\mathrm{c}} \pm 0,58$ & $2,21^{\mathrm{c}} \pm 0,55$ & $2,09^{\mathrm{c}} \pm 0,57$ & $1,97^{\mathrm{c}} \pm 0,54$ \\
\hline
\end{tabular}

Os resultados são médias com as respectivas estimativas de desvio padrão; letras diferentes na mesma linha - diferença significativa (p < 0,05 ) pelo teste de Tukey; e letras iguais na mesma linha - diferença não significativa $(\mathrm{p}>0,05)$. 


\section{Referências bibliográficas}

ANDERSON, J. S. et al. Fish meal quality assessment for Atlantic salmon (Salmo salar L.) reared in sea water. Aquaculture Nutrition, v. 3, p. 25-28, 1997.

ANDRIGUETTO, J. M. et al. Nutrição animal. 6 ed. São Paulo: Nobel, 1999. v. 1.

ANFAL. Indústria Brasileira de Alimentação Animal. Perfil 2002. Disponível em: <http://www.anfal.org.br>. Acesso em: 21 Jun. 2006.

BLIGH, E. G.; DYER, W. J. A rapid method of total lipid extraction and purification. Canadian Journal Biochemistry Physiology, v. 37, n. 8, p. 911-917, aug. 1959.

BRAGADÓTTIR, M.; PÁLMADÓTTIR, H.; KRISTBERGSSON, K. Composition and Chemical Changes during Storage of Fish Meal from Capelin (Mallotus villosus). Journal of Agricultural and Food Chemistry, v. 52, n. 6, p. 1572-1580, 2004.

BRESSAN, M. C. et al. Composição de ácidos graxos dos cortes comerciais de capivara (Hydrochaeris hydrochaeris L. 1766). Ciências Agrotécnicas, v. 28, n. 6, p. 1352-1359, nov./dez. 2004.

BRASIL. Ministério da Agricultura e Abastecimento. Sindicato Nacional da Indústria de Alimentação Animal. Associação Nacional dos Fabricantes de Rações. Compêndio brasileiro de alimentação animal. São Paulo: ANFAR/CBNA/SDR, 2005.

BRUMANO, G. et al. Composição química e valores de energia metabolizável de alimentos protéicos determinados com frangos de corte em diferentes idades. Revista Brasileira de Zootecnia, v. 35, n. 6, p. 2297-2302, 2006.

CUNNIFF, P. (Ed.). Official methods of analysis of AOAC international. 16. ed. Gaithesburg: AOAC International, 1997. v. 1.

DUTSON, T. R. The measurement of $\mathrm{pH}$ in muscle and its importance to meat quality. In: RECIPROCAL MEAT CONFERENCE, 36, 1983, Chicago. Proceedings... Chicago, p. 92-97, 1983.

FARIA, A. C. E. A.; HAYASHI, C.; SOARES, C. M. Farinha de Vísceras de Aves em Rações para Alevinos de Tilápia do Nilo, Oreochromis niloticus (L.). Revista Brasileira de Zootecnia, v. 31, n. 2, p. 812-822, 2002.

GIANNONI, M. L. Viabilidade da exploração de ratitas em São Paulo. Biológico, v. 1, n. 2, p. 91-96, jul./dez. 1998.

GIANNONI, M. L. Criação de avestruzes e emas. São José do Rio Preto: [s.n.], 2001. 55 p. (Apostila).

GONÇALVES, E. G.; CARNEIRO, D. J. Coeficientes de Digestibilidade Aparente da Proteína e Energia de Alguns Ingredientes Utilizados em Dietas para o Pintado (Pseudoplatystoma coruscans). Revista Brasileira de Zootecnia, v. 32, n. 4, p. 779-786, 2003.

HILDEBRAND, M. Análise da estrutura dos vertebrados. São Paulo: Atheneu, 1995. 700 p.

James, C. S. Analytical chemistry of foods. London: Blackie Academic \& Professional, 1996. p. 53-59.

JORGE NETO, G. Qualidade nutricional do subproduto de graxaria avícola. In: Abate e processamento de frangos. Campinas: Fundação APINCO de Ciência e Tecnologia Avícolas, 1994. p. 119-128.

MEDEIROS, M. F. D. et al. Desidratação de subprodutos da industrialização do escargot. In: CONGRESSO BRASILEIRO DE CIÊNCIA E TECNOLOGIA DE ALIMENTOS, 18, 2000, Fortaleza. Resumos... Fortaleza: Sociedade Brasileira de Ciência e Tecnologia de Alimentos, v. 3, p. 11-72, 2000.

MERRIL, A. L.; WATT, B. K. Energy value of foods: basis and derivation. Washington, United States: Department of Agriculture, 1975. (Handbook, n. 456).
MEURER, F.; HAYASHI, C.; BOSCOLO, W. R. Digestibilidade Aparente de Alguns Alimentos Protéicos pela Tilápia do Nilo (Oreochromis niloticus). Revista Brasileira Zootecnia, v. 32, n. 6, p. 1801-1809, 2003. (Suplemento 2).

NASCIMENTO, A. H. et al. Composição química e valores de energia metabolizavel das farinhas de penas e vísceras determinados por diferentes metodologias para aves. Revista Brasileira de Zootecnia, v. 31, n. 3, p. 1409-1417, 2002.

NAUGHTON, J. M.; O’DEA, K.; SINCLAIR, A. J. Animal foods in tradicional aboriginal diets: polyunsaturated and low in fat. Lipids, v. 21, n. 11, p. 684-690, 1986.

NUNES, R. V. et al. Valores energéticos de subprodutos de origem animal para aves. Revista Brasileira Zootecnia, v. 34, n. 4, p. 1217-1224, 2005.

NYINA WAMWIZA, L.; WATHELET, B.; KESTEMONT, P. Potential of local agricultural by-products for the rearing of African catfish Clarias gariepinus in Rwanda: effects on growth, feed utilization and body composition. Aquaculture Research, v. 38, p. 206-214, 2007.

OCKERMAN, H. W.; HANSEN, C. L. Industrialización de subprodutos de origem animal. Zaragoza: Acribia, 1994. 387 p.

Oliveira, J. E. D.; Santos, A. C.; Wilson, E. D. Nutrição básica. São Paulo: Sarvier, 1982. p. 79-97.

PAGANO, M; GAUVREAU, K. Princípios de Bioestatística. Tradução Luiz Sergio de Castro Paiva. São Paulo: Pioneira Thomson Learning, 2004. 506 p.

PARDI, M. C. et al. Ciência, higiene e tecnologia de carne. Goiânia: EDUFF, 1993. 1110 p.

PEZZATO, L. E. et al. Digestibilidade Aparente de ingredientes pela Tilápia do Nilo (Oreochromis niloticus). Revista Brasileira de Zootecnia, v. 31, n. 4, p. 1595-1604, 2002.

PRICE, J. F.; SCHWEIGERT, B. S. Ciência de la carne y de los produtos carnicos. Zaragoza: Acribia, 1994. 581 p.

ROSMINI, M. R. et al. TBA test by extractive method applied to paté. Meat Science, v. 42, n. 1, p. 103-110, 1996.

SCHNEIDER, I. S. Processamento industrial de aves e seus subprodutos. São Paulo: Editora Brasileira da Agricultura, 1973. 98 p.

SCRIBONI, A. B. Perfil dos ácidos graxos da gordura intramuscular e da gordura aparente da ema (Rhea americana). São José do Rio Preto, 2006. 84 f. Dissertação - (Mestrado em Engenharia e Ciência de Alimentos), Instituto de Biociências, Letras e Ciências Exatas, Universidade Estadual Paulista - UNESP.

SINCLAIR, A. J.; O'DEA, K. Fats in human diets though history: is the western diet out of step? In: WOOD, J. D.; FISHER, A. V. Reducing fat in meat animals. London: Elsevier, 1990. p. 1-47.

SINDIRAÇÕES. Sindicato Nacional da Indústria de Alimentação Animal. Disponível em: <http:// www.sindiracoes.org.br $>$. Acesso em: 02 maio 2007.

SILVA, D. J. Análise de alimentos: métodos químicos e biológicos. Viçosa: Universidade Federal de Viçosa, 1990. 166 p.

SOUZA, J. R. S. T.; CAMARÃO, A. P.; RÊGO, L. C. Degradabilidade ruminal da matéria seca e proteína bruta de subprodutos da agroindústria, da pesca e de abatedouros em caprinos. Brazilian Journal of Veterinary Research and Animal Science, São Paulo, v. 37, n. 2, 2000. Disponível em: <www.scielo.br>. Acesso em: abril 2007. 